\title{
Complications of Circumcision: A Three-Year Experience in N'Djamena Mother \& Child Hospital (Chad)
}

\author{
Mahamat Ali Mahamat ${ }^{1,2 *}$, Olivier Ngueringem ${ }^{1,3}$, Mohamed Jalloh', Mahamat Nour ${ }^{1,3}$, \\ Vadandi Valantin ${ }^{1,2}$, Oradimo Sylvain ${ }^{1,3}$, Lamine Niang', Serigne M. Gueye ${ }^{4}$ \\ ${ }^{1}$ The University of N'Djamena, N'Djamena, Chad \\ ${ }^{2}$ The General Hospital of National Reference of N'Djamena, N'Djamena, Chad \\ ${ }^{3}$ The N'Djamena Mother and Child Hospital, N'Djamena, Chad \\ ${ }^{4}$ Grand Yoff General Hospital (HOGGY) of Dakar, Dakar, Senegal \\ Email: "doctaali@yahoo.fr
}

Received 28 January 2016; accepted 8 April 2016; published 11 April 2016

Copyright (C) 2016 by authors and Scientific Research Publishing Inc.

This work is licensed under the Creative Commons Attribution International License (CC BY). http://creativecommons.org/licenses/by/4.0/

(c) (†) Open Access

\section{Abstract}

Aim: This study aimed at describing the various aspects of complications of circumcision and their management in patients referred to N'Djamena Mother \& Child Hospital (Chad). Material and Methods: All patients referred for complications of circumcision reported on a 3-year period (July 2011-May 2014) were included. Demographic data, circumstances of the circumcision, clinical presentation and management were computed. Results: Thirty-one cases of complications from traditionally performed circumcisions $(n=19)$ or circumcisions were performed by paramedics $(n=12)$. The average age was $7.5 \pm 2$ years. More than $60 \%$ of the patients were between 6 and 10 years old. The complications reported included: urethral fistula in the balano preputial sulcus in 10 cases $(32 \%)$, entire amputation of the glans in 2 cases $(6.5 \%)$, amputation of the penis in one case $(3.5 \%)$, stenosis of the urethral meatus in 8 cases $(26 \%)$, bleeding in 5 cases $(16 \%)$ and infections in 5 cases $(16 \%)$. A surgical treatment was performed according to clinical cases. Conclusion: Circumcision is safe when performed in hospitals. Unfortunately, serious complications may occur if it is performed by non-experts. Hence there is a necessity to raise people's awareness on the importance of the medicalization of circumcision.

\section{Keywords}

Accident, Circumcision, Medicalization, Chad

\footnotetext{
${ }^{*}$ Corresponding author.
} 


\section{Introduction}

Circumcision is a surgical operation consisting on partially or completely removing the foreskin. It is assumed that $25 \%$ of men (male) worldwide are circumcised [1]. Bearing this in mind, it is clear that circumcision is the most performed surgical operation worldwide [2]. Most circumcisions are due to religious reasons and some to medical ones [3]. In Africa, circumcision is mostly performed by traditional practitioners, sometimes by qualified or non-qualified paramedics with limited or no knowledge about anatomy, surgery and asepsy [4]. In Chad, circumcisions are commonly performed at home and in the villages, during collective circumcisions rites; this often leads to major complications; few cases of circumcisions are performed in health facilities. Complications related to circumcision are benign or severe, sometimes sexual, urinary and life threatening for patients. In developed countries, the rate of circumcision related complications ranges from $2 \%$ to $5 \%$ [5]. In developing countries, circumcision related complications rate is rather higher; up to $85 \%$ when performed by traditional practitioners [6]. This study aimed at identifying and describing the complications of circumcision in patients referred to the Paediatric Surgery Department of the Mother \& Child Hospital and the clinical management.

\section{Patients and Methods}

All patients admitted in the pediatric surgery unit for a complication following circumcision were included. 19 cases of circumcision have been performed by traditional practitioners versus 12 cases by paramedics. For these patients medical record abstraction was used to collect data. The variable of interest were patient age, area of circumcision performance, cirumcision method, healthcare provider, time to referral to the hospital for complication management, reason for referral and clinical presentation. Laboratory work included blood cell count and hemoglobin. Type of complication, medical and surgical treatment and outcomes were the remaining variables. Complications were further grouped as penile urethral fistula; urethral meatus stenosis; bleeding; infections and amputation. We performed descriptive analysis of the variable, statistical significance was considered for $\mathrm{p}<$ 0.05 .

\section{Results}

The distribution of patients by age is reported in (Figure 1). The average age of the patients was $7.5 \pm 2$ years, ranging from 1 to 12 years. There was a predominance of the 6 - 10 years age group (61.9\%). In $69.6 \%$ of cases the circumcisions were performed by traditional practitioners versus $39.4 \%$ by paramedics. The various complications are reported in (Figure 2). Two cases of glans amputation and one case of complete amputation of the

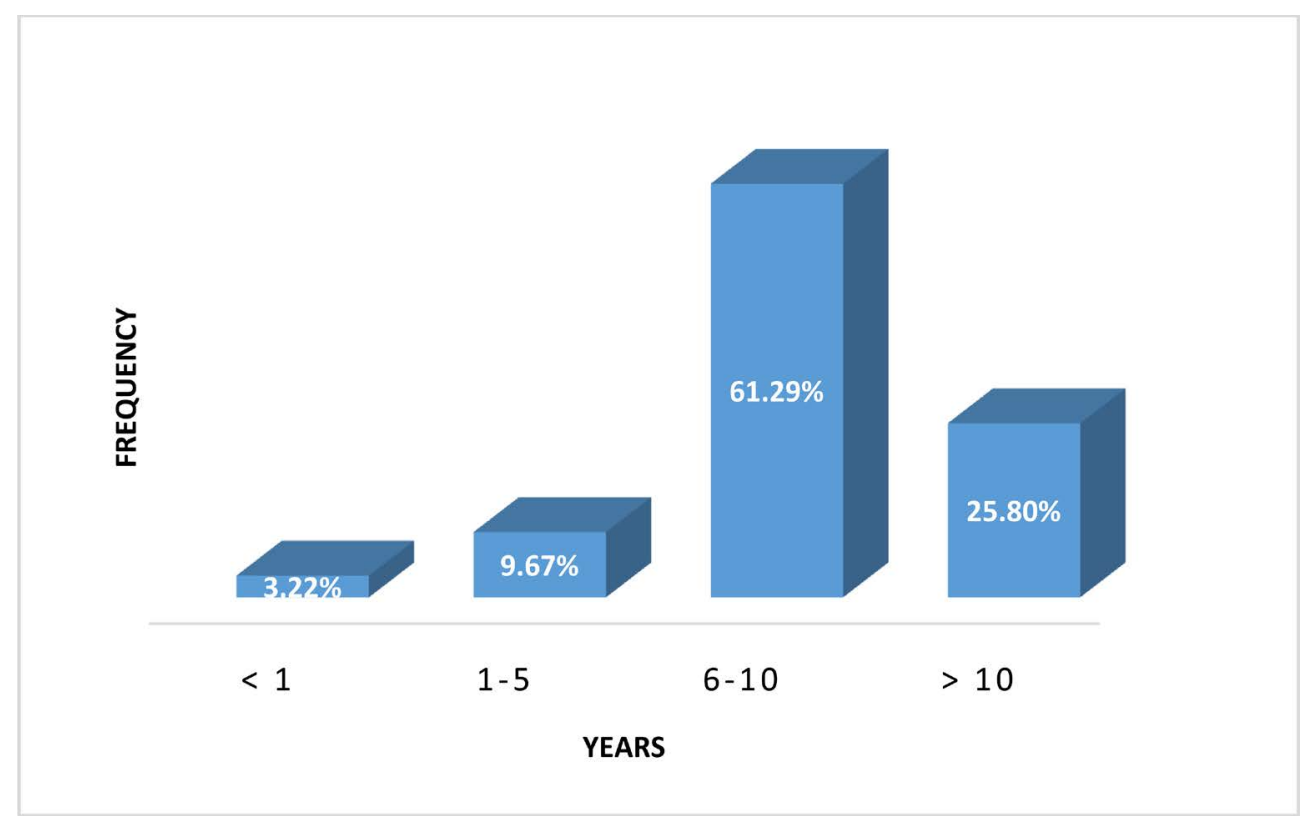

Figure 1. Distribution of the patients according to age group. 
penis were recorded. A meatoplasty with a placement of a trans-urethral catheter was carried out for 8 cases of urethral meatus stenosis, for 1 case of glans amputation admitted too late, as well as for 1 case of failure of replantation of the penis after amputation (Table 1 ).

One (1) case of amputation of the glans was performed by a paramedic and then admitted to the department within 30 minutes. The amputated penis was put in fresh saline. It was immediately brought to the operating room (Figure 3) and the glans was successfully replanted (Figure 4).

Overall, the result of the treatment was satisfactory in $78 \%$ of cases.

\section{Discussion}

Although circumcision-related accidents occur in developed countries, they are much commonest in developing countries. In Africa, circumcision is usually performed by people without any medical competency (hairdresser, traditional healer, paramedics...) [7]. However, many parents, often illiterate, unaware of the seriousness of potential accidents, and wishing to avoid lengthy hospital administrative procedures and general anaesthesia, considered too risky for such a simple operation, choose providers without any medical skills [8].

In our study over 3 years we report 31 accidents. The frequency of these complications is comparable to those

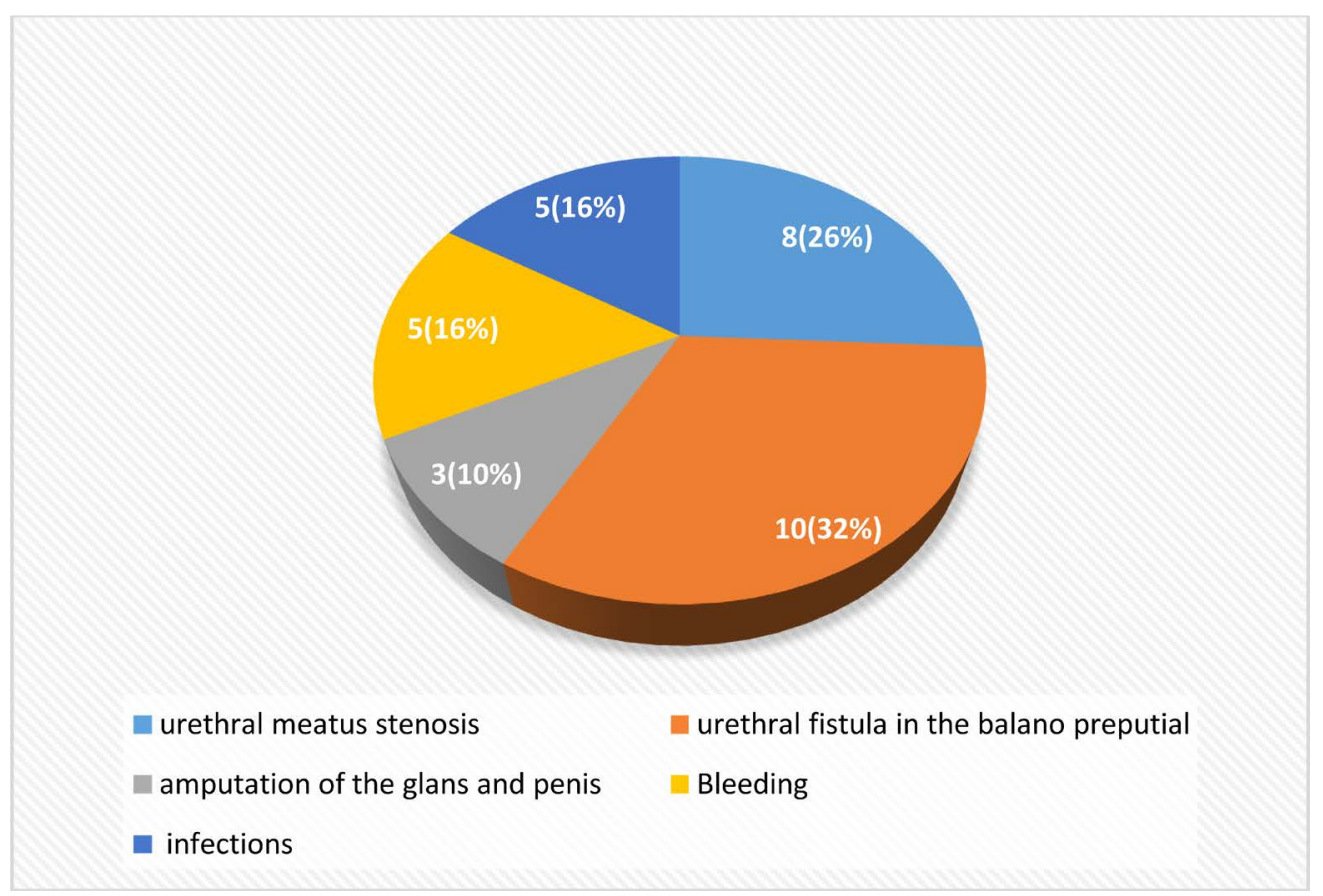

Figure 2. Distribution of complications.

Table 1. Distribution of the surgical technic according to types of lesion.

\begin{tabular}{|c|c|c|c|c|}
\hline Type of lesion & \multicolumn{2}{|l|}{ Treatment } & Number of patients & Percentage \\
\hline Amputation of glans & \multicolumn{2}{|c|}{ Replantation of the glans } & 1 & 3.23 \\
\hline Amputation of glans & Replantation of the glans & Meatoplasty & 1 & 3.237 \\
\hline Amputation of penis & replantation of the penis e & Meatoplasty & $\zeta \quad 10$ & 32.26 \\
\hline Urethral stricture & \multicolumn{2}{|l|}{ Meatoplasty } & $8 J$ & $25.80 J$ \\
\hline Urethral fistula & \multicolumn{2}{|c|}{ Fistula closure } & 10 & 32.26 \\
\hline Haemophilia bleeding & \multicolumn{2}{|c|}{ Blood transfusion + local care } & 2 & 6.46 \\
\hline Haemorrhage due to haemostasis failure & \multicolumn{2}{|c|}{ Haemostasis by sutures + local care } & 3 & 9.67 \\
\hline Local suppuration & \multicolumn{2}{|c|}{ Local care + antibiotics } & 5 & 16.12 \\
\hline Total & & & 31 & 100 \\
\hline
\end{tabular}




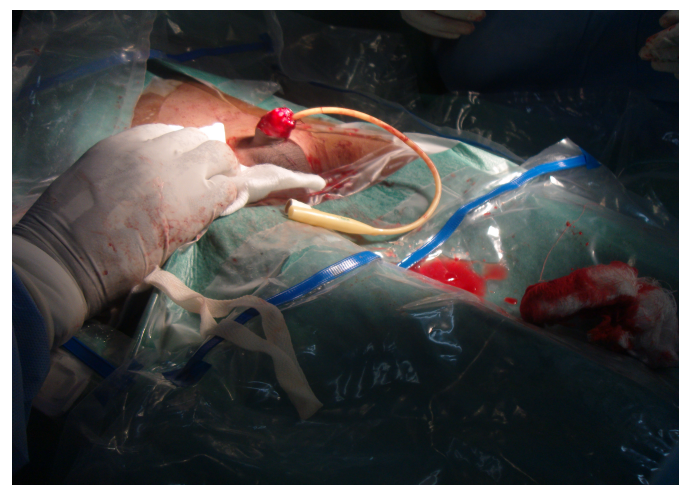

Figure 3. Amputation of glans admitted in 30 minutes.

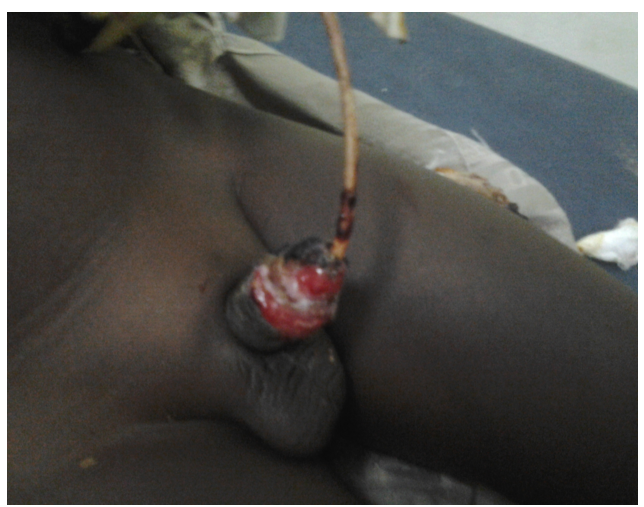

Figure 4. 10 days after replantation.

reported by FETTE [9] in Austria with 20 cases over 1 year; by BA [10] in Senegal with 26 cases over 2 years and by Sylla et al. [11] in Senegal with 63 cases over 11 years.

This higher incidence in our study could be explained by the policy of free access to emergency care, in Chad Health System. Our department being a national referral center, the reference of patients from other health institutions is therefore common.

The mean age of the patients in our study was $7.5 \pm 2$ years, ranging from 1 to 12 years. There is a predominance of the age group 6 - 10 years. However many series reported lower mean age. NIGEL [12] reported a mean age of 4.2 years, and AHMED [13] a mean age of 4 years in Nigeria. As for SYLLA [11] and DIALLO [14], they respectively reported a mean age of $10.5 \pm 6.7$ years and $11.8 \pm 6.9$ years. There is no consensus as to the age for circumcision; such age depends on the customs of each people [15]. Thus, in our work environment, circumcision, which is performed among some ethnic groups by the end of the childhood, consists of a sacred act that grants the teenager the recognition and acceptance from the men's community, in preparation for a perfect sexuality in adulthood. Some American authors [16] [17] suggest that circumcision in the neonatal period has better prophylactic effects on some infections than the one performed later in adulthood.

The time to consultation in a specialized center depends on the types of complication. Our mean time to consultation was $20 \pm 2$ days, ranging from 30 minutes to about 1 year. Thus, haemorrhagic accidents, glans and penis amputation were seen in emergency qickly, while other complications were seen at a later stage, sometimes years after the occurrence of the accident. Such complications include urethral fistulas and urethral meatus strictures. These findings corroborate those of some African authors [11] [14], but this period is shorter in the Western studies [18]-[20].

In our study, $69.6 \%$ of cases of circumcision were traditionally performed and $31.4 \%$ of cases by a paramedical staff. A study by Sylla et al. [11] revealed a predominance of circumcisions traditionally performed concerning 63 cases $(71.42 \%)$. The higher frequency of complications in traditionally performed circumcisions is also reported by Ahmad in Nigeria [13]. This higher rate of traditionally performed circumcisions suggests the inadequacy and sometimes lack of health facilities and trained medical or paramedical staff in some of our re- 
gions, as well as the influence of some beliefs and rites [11].

\subsection{Penile Urethral Fistula}

It is the most frequently reported complication in our series (64.2\%). AKPO [21] in a study over 6 years in Benin reported 4 cases of penile urethral fistula, BASKIN [18] in a study over 3 years in France reported 8 cases, and BENCHEKROUN [22] in a study over 10 years in Morocco reported 15 cases. Most $(n=8)$ of these fistulas in our study were caused by a traditionally performed circumcision. This observation was made by BITHO et al. [15] and most authors agree that the coronal sulcus is the main site of the fistula. In fact, in this zone urethra is thinner and possible adhesions between glans and foreskin make it more vulnerable. Most fistulas occur at the time of arterial haemostasis [13]. Rather, some authors believe that fistula is facilitated by local infection [23].

Fistula closure method used in our series is the freshening and duplication technique of urethral, with subcutaneous suture divided in two layers (10 cases). With this technique, we immediately had 8 cases of favourable outcome. This technique was also chosen by BENCHEKROUN [22] who achieved closure in 10 cases. BASKIN [18] opted for the use of a foreskin flap, while BA [10] preferred Davis uretrorraphy by endo urethral suture. Whatever the technique used, a fundamental principle of the urethral surgery shall be respected: the absence of overlap of skin and urethral sutures [11].

Urinary diversion after the treatment of the fistula is highly questioned. In our series all the patients $(\mathrm{N}=10)$ underwent supra pubic catheterization. Ba et al. [10] and Benchekroun et al. [22] opted for cystostomy. For some authors [10] [11] [22] the supra pubic catheterization is advantageous: it enables the freshly repaired area "to rest and dry", avoiding then the possible disadvantages of a transurethral catheterization; it also enable tension free sutures and avoid infections.

In our study, treatment outcomes were generally satisfactory (78\% success). These findings are similar to those by other authors [14] [22]. In his series, BASKIN [18] reported 100\% of successful outcomes.

\subsection{The Urethral Meatus Stenosis}

It often occurs a long time subsequently to the circumcision given that it is rarely found in uncircumcised persons [20].

Meatus stenosis is caused either by unnoticed minimal trauma of the urethral meatus during circumcision, or by an infection [11]. Some researchers support it may be due to irritation of the urethral meatus left uncovered by circumcision [24]. Difficulty passing urine remains the main reason for consultation. Diagnosis is most often based on clinical examination. Urethrocystography is generally carried out only to exclude associated urethral pathology or to appreciate the impact on bladder or upper tract. Thus, HANUKOGLN [25] reports a case of bilateral upper tract dilation in a child after complete amputation of the glans and stenosis of the urethral orifice. This urethral meatus stenosis sometimes causes recurrent urinary infections [26].

All our patients underwent a meatoplasty. Such a procedure was used by other authors [26]. Urinary drainage was performed by transurethral foley cathether in most cases. However, some authors think that transurethral catheterization is not necessary after meatoplasty [27]. BITHO suggested a catheterization to dilate the meatus [15] in case of treatment failure, in order to maintain a good gauge of the neo-urethral meatus.

In our series, the therapeutic outcomes based of the urinary stream were satisfactory in most cases $(80.1 \%$ of cases), as underlined by several authors [26]. Sylla et al. [11] reported 2 failures after meatoplasty, resulting in the persistence of the stenosis.

\subsection{Bleeding Complications}

Bleeding remains a common circumcision related-complication. Parents consult early because they concerned. Bleeding is usually benign but can sometimes become severe if prolonged, which was the case in 5 cases of our series. Bleeding most often results from haemostasis failure by the operator, or from a haemostatic disorder (haemophilia). It can therefore be extremely severe, leading to potential life-threatening complications. Two cases of our series were related to haemophilia. In both cases the outcome was favourable after blood transfusion. Deaths due to bleeding were reported by other authors [20] [27]. ABDOU RAOUF [28] in Gabon reported 6 deaths out of 48 cases of bleeding as a result of circumcision. The other 3 cases of bleeding in our series were related to haemostasis failure, which was corrected by ligation of small vessels that were bleeding. The transfusion of iso-group iso-rhesus blood is barely indicated; given that the child is referred before any life threatening 
status was reached. The surgical exploration of the wound with complementary haemostasis is necessary in case of persistent bleeding.

\subsection{Infections}

Post circumcision infections may be local (local suppuration) or global (septicaemia). In this study, 5 cases of infection by local suppuration were found. The suppuration reported in our study suggests improving asepsis and post operative management. Such infections are related to a poor understanding asepsis and hygiene requirement. The treatment relies on local care [20] and on a well oriented antibiotherapy.

We did not find any septicaemia in our series unlike Sylla et al. [11] who reported one case.

\subsection{Amputation}

The amputation of the penis, a rather rare accident, was reported in 3 patients of our series. Finally, according to Bitho et al. [15] amputation of glans or the penis, one of the most severe complications of circumcision reflects the incompetence of the practitioner [15]. It is the direct consequence of the ignorance of the procedure. We have reported 3 cases of amputation (two of the glans and one of the penis), all of them resulting from circumcision performed by a paramedic; one of our patients was seen three hours after the accident, another at after effects stage. Treatment in both cases consisted of meatoplasty after a failed implantation for the second case. The third case arrived at the emergency room 30 minutes after the accident, the operator was a paramedic, and he personally led the child with the cut glans at the hospital. The re-implantation was successfully performed. Glukman et al. [19] reported a case of a new-born penis cut that was successfully replanted 3 hours after amputation. One of the two re-implantations reported by Ba [10], was successful. In both cases the time from the amputation of the glans to the repair was not more than 3 hours. Sherman et al. [29] stressed on a good viability of amputated tissues until the eighth hour after the accident. The re-implantation of the glans should be attempted when possible. The amputated part should be immersed in a shelf or in a physiological saline solution and kept at $4^{\circ} \mathrm{C}$ with the addition of an antibiotic and possibly heparin [30]. This type of injury can be avoided by doing a proper traction on the foreskin, placing a clamp over the glans previously identified and stuck by the thumb over the glans. Since the population considers circumcision a minor operation, documentation of such lesions, even if rare, can help to prevent it. This is especially important in countries where circumcision is usually performed by unqualified traditional healers, where complications are not always reported, and where the follow-up is no always implemented [7].

Some existing anatomo clinical post circumcision aspects were not mentioned in our series; they include scar phimosis, hemi-scrotum amputation, and pseudo-elephantiasis of the penis as well as striping of the penis.

The limitations of the study are represented by the small sample size and the lack of systematic referral of cases. Data on long term follow-up are also limited. Despite these limitations we believe it is important to do this report and keep tracking and preventing complications to reduce the public health impact and circumcision related complications.

\section{Conclusion}

Circumcision is the commonest surgical operation performed worldwide. In Chad, it is often performed at home, either traditionally by inexperienced persons or by non-trained paramedics. Such a situation is likely to cause serious urinary or/ sexually, and sometimes vital complications. Therefore, in order to prevent such accidents, circumcision, even for religious reasons, should be performed by a surgeon. The best treatment consists of training staff to perform circumcisions along with as prevention, which requires education of the population on the importance of medicalization of circumcision.

\section{References}

[1] Rizvi, S., Nagvi, S., Hussain, M. and Hasan, A. (1999) Religious Circumcision: A Muslim View. British Journal of Urology International, 83, 13-16. http://dx.doi.org/10.1046/j.1464-410x.1999.0830s1013.x

[2] Atikeler, M.K., Onur, R., Gecit, I., Senol, F.A. and Cobanoglu, B. (2001) Increased Morbidity after Circumcision from a Hidden Complication. British Journal of Urology International, 88, 938-940. http://dx.doi.org/10.1046/j.1464-4096.2001.02416.x 
[3] Moses, S., Bailey, R. and Ronald, A. (1998) Male Circumcision: Assessment of Health Benefits and Risks. Sexually Transmitted Infections, 74, 368-373. http://dx.doi.org/10.1136/sti.74.5.368

[4] Doré, B. (1997) Circoncision chez le nouveau-né et l’enfant. In Urologie pédiatrique ECU. Laboratoires Synthélabo, France, 154-157.

[5] Ruffion, A., Azam, P. and Leriche, A. (2003) Reconstruction de la verge. In: Encycl. Méd. Chir., Techniques chirurgicales-Chirurgie plastique reconstructrice et esthétique, 45-686, Techniques chirurgicales-Urologie, Elsevier, Paris, 41478.

[6] Yilmaz, A.F., Sarikaya, S., Yildiz, S. and Buyukalpelli, R. (1993) Rare Complication of Circumcision: Penile Amputation and Reattachment. European Urology, 23, 423-424.

[7] Essid, A., Hamzaoui, M., Sahli, S. and Houissa, T. (2005) Réimplantation balanique après accident de circoncision. Progrès en Urologie, 15, 745-747.

[8] Gross, P., Pages, R. and Bondelat, D. (1986) Complications de la circoncision rituelle. Chirurgie Pediatrique, 27, 224225.

[9] Fette, A., Schleef, J. and Haberlik, A. (2000) Circumcision in Pediatric Surgery Using an Ultrasound Dissection Scalpel. Technology and Health Care, 8, 75-79.

[10] Ba, M., Ndoye, A., Fall, A., Sylla, C., Gueye, S.M. and Diagne, B.A. (2000) Les fistules péniennes après circoncision: A propos de 20 observations. Andrologie, 10, 75-77. http://dx.doi.org/10.1007/BF03035226

[11] Sylla, C., Diao, B., Diallo, A.B., Fall, P.A., Sankale, A.A. and Ba, M. (2003) Les complications de la circoncision. A propos de 63 cas. Progrés en Urologie, 13, 266-272.

[12] Nigel, W., Julian, C. and Kapila, L. (1993) Why Are Children Referred for Circumcision? BMJ, $306,28$.

[13] Ahmed, A., Mbibin, H., Danam, D. and Kalayig, D. (1999) Complications of Traditional Mate Circumcision. Annals of Tropical Paediatrics, 19, 133-137.

[14] Diallo, A.B., Toure, B.M., Camara, C., Barry, M., Bah, I., Keita, M., et al. (2008) Les accidents de la circoncision: Aspects anatomo-cliniques et thérapeutiques au CHU de Conakry, Guinée. A propos de 44 cas. Andrologie, 18, 10-16. http://dx.doi.org/10.1007/BF03040374

[15] Bitho, M.S., Sylla, S., Toure, K., Akpo, C., Boukary, I., Mensah, A., et al. (1975) Les accidents de la circoncision et de l'excision en milieu africain. Bulletin de la Societe Medicale d'Afrique Noire de Langue Francaise, 20, 249-255.

[16] Niku, S.D., Stock, J.A. and Kaplan, G.W. (1995) Neonatal Circumcision. Urologic Clinics of North America, 22, 57-65.

[17] Warner, E. (1981) Benefits and Risks of Circumcision. Canadian Medical Association Journal, 125, 967-976.

[18] Baskin, L.S., Canning, D.A., Snyderh, M. and Duckett, J.W. (1997) Traumatismes iatrogènes de l'urètre au cours des circoncisions: Réparation chirurgicale. Journal d'Urologie, 157, 2269-2271. http://dx.doi.org/10.1016/S0022-5347(01)68233-8

[19] Gluckman, G.A., Stoller, M.L., Jacobs, M.M. and Kogan, B.A. (1995) Newborn Penile Glans Amputation during Circumcision and Successful Reattachment. Journal d'Urologie, 153, 778-779. http://dx.doi.org/10.1016/S0022-5347(01)67718-8

[20] Williams, N. and Kapila, L. (1993) Complications of Circumcision. British Journal of Surgery, 80, 1231-1236. http://dx.doi.org/10.1002/bjs.1800801005

[21] Akpo, C., Hodonou, R., Goudote, E. and Hounnasso, P. (1998) La pathologie urétrale chez l'enfant dans les services chirurgicaux du CHU de Cotonou. A propos de 77 cas. Annale d'Urologie, 32, 370-374.

[22] Benchekroun, A., Lakrissa, A., Tazia, H. and Ouazzani, N. (1981) Fistules urétrales après circoncision. A propos de 15 cas. Revue Maroc Medical, 3, 2-3.

[23] Johnsons, S. (1949) Persistent Urethral Following Circumcision. US Navy Medical Bulletin, 49, 120-122.

[24] Gairdner, D. (1949) The Fate of the Foreskin. A Study of Circumcision. BMJ, 2, 1433. http://dx.doi.org/10.1136/bmj.2.4642.1433

[25] Hanukogln, A., Danielle, L., Katzir, Z., Gorenstein, A. and Fried, D. (1995) Serious Complications of Routine Ritual Circumcision in a Neonate. European Journal of Pediatric, 154, 314-315.

[26] Upadhyay, V., Hammodat, H.M. and Pease, P.W. (1998) Post Circumcision Meatal Stenosis: 12 Years’ Experience. New Zealand Medical Journal, 27, 57-58.

[27] Boccon-Gibod, L. (1993) Cure chirurgicale des rétrécissements de l’urètre masculin. Editions Techniques. Encycl. Méd. Chir. (Paris-France), Traité de Techniques chirurgicales. Urologie-Gynécologie, 41-320, 27 p.

[28] Christakiss, D.A., Harvey, E., Zerr, D.M. and Connel, F.A. (2000) A Trade of Analysis of Routine Newborn Circumci- 
sion. Pediatrics, 105, 246-249. http://dx.doi.org/10.1097/00006254-200009000-00010

[29] Raouf, O.A., Josseaum, A. and Tchoua, R. (2005) Complication de la circoncision rituelle. Médecine d'Afrique Noire, 52, 366-368.

[30] Sherman, J., Borer, J., Horwltz, M. and Glassberg, K.I. (1996) Circumcision: Successful Glanular Reconstruction and Survival Following Traumatic Amputation. Journal d'Urologie, 156, 842-844. 